\title{
BMJ Open Traffic pollution at the home address and pregnancy outcomes in Stockholm, Sweden
}

\author{
David Olsson, ${ }^{1}$ Ingrid Mogren, ${ }^{2}$ Kristina Eneroth, ${ }^{3}$ Bertil Forsberg ${ }^{1}$
}

To cite: Olsson D, Mogren I, Eneroth $\mathrm{K}$, et al. Traffic pollution at the home address and pregnancy outcomes in Stockholm, Sweden. BMJ Open 2015;5:e007034. doi:10.1136/bmjopen-2014007034

- Prepublication history for this paper is available online. To view these files please visit the journal online (http://dx.doi.org/10.1136/ bmjopen-2014-007034).

Received 27 October 2014 Revised 5 June 2015 Accepted 19 July 2015

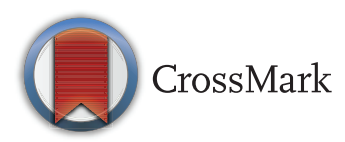

${ }^{1}$ Department of Public Health and Clinical Medicine, Occupational and Environmental Medicine, Umeå University, Umeå, Sweden

${ }^{2}$ Department of Clinical Sciences, Obstetrics and Gynecology, Umeå University, Umeå, Sweden

${ }^{3}$ Environment and Health Administration, Stockholm, Sweden

Correspondence to Dr David Olsson; david.olsson@envmed.umu.se

\section{ABSTRACT}

Background: For the past two decades, several studies have reported associations between elevated levels of ambient air pollution and adverse pregnancy outcomes, although with varying conclusions.

Objectives: To examine possible associations between the traffic pollution situation at the home address, for women who did not change address during pregnancy, and three types of pregnancy outcomes: spontaneous preterm delivery, children born small for gestational age (SGA) and pregnancy-induced hypertensive disorders.

Methods: We used data for the Greater Stockholm Area from the Swedish Medical Birth Register to construct a cohort based on all pregnancies conceived between July 1997 and March 2006, n=100 190. The pregnancy average nitrogen oxide, NOx, levels and annual mean daily vehicles at the home address were used as exposure variables. Mixed-model logistic regression was performed to assess any associations between exposure and outcome.

Results: There was an association between elevated traffic pollution exposure during pregnancy and pregnancy-induced hypertensive disorders. A $10 \mu \mathrm{g} / \mathrm{m}^{3}$ increase in the pregnancy average NOx level at the home address resulted in an OR of $1.17(95 \% \mathrm{Cl} 1.10$ to 1.26). The 2nd to 4th quartiles of NOx were all associated with an increased risk of SGA, but there was no difference in the risk estimate among the higher quartiles. There was a tendency of a higher risk of spontaneous preterm delivery in relation to higher levels of NOx. There was no evidence of an association between vehicle flow, the cruder indicator of traffic pollution, and the studied outcomes in this study. Conclusions: In this large cohort, there was a fairly strong association between vehicle exhaust levels at the home address and pregnancy-induced hypertensive disorders, after adjustment for important risk factors.

\section{INTRODUCTION}

A growing number of studies investigate the associations between air pollution and adverse perinatal outcomes such as preterm birth and small for gestational age (SGA), which are important predictors for health during childhood and also later in life.

\section{Strengths and limitations of this study}

- Large register-based study, with comprehensive data on birth outcomes in the area.

- High resolution in the spatial exposure assessment.

- Not able to identify specific time windows of exposure.

- Home addresses are not geocoded to exact coordinates, but to $100 \times 100 \mathrm{~m}^{2}$.

Several recent reviews added to the previously published papers. ${ }^{1-5}$ These papers show that a large number of epidemiological studies from different parts of the world have reported not only adverse effects of air pollution on birth outcomes and pregnancy complications such as preeclampsia, but also that the results vary with respect to significant pollutants and time windows of susceptibility. ${ }^{6-17}$

Preterm birth is known to be an important predictor of childhood effects on the respiratory, gastrointestinal, immunologic and central nervous systems, educational performance, growth and health later in life. ${ }^{18-21}$ Preeclampsia is a disorder characterised by hypertension and proteinuria; it is an important cause of induced preterm delivery to prevent the progression of the disorder. ${ }^{22}$ Preeclampsia is more common when the pregnant woman is nulliparous, obese or suffers from chronic hypertension, kidney disease or diabetes mellitus. ${ }^{23}$ SGA in most cases is a result of intrauterine growth restriction. Preeclampsia, pregnancy-induced hypertension, placental insufficiency and smoking are risk factors for SGA. ${ }^{23} 24$

Motor vehicle traffic is the major local source of ambient air pollution in most modern cities, causing within-city gradients in nitrogen oxides (NOx), exhaust particles (nanoparticles), road wear (coarse particles), carbon monoxide and many hydrocarbons and, to a lesser extent, in fine particles $\left(\mathrm{PM}_{2.5}\right)$. Traffic pollutants, including primary 
combustion particles, are responsible for a large part of the adverse health effects associated with exposure to particle mass and nitrogen dioxide $\left(\mathrm{NO}_{2}\right)$, especially in cities. $^{25}$

The approaches to estimate pregnant women's exposures to air pollutants have been very different and are changing over time towards a finer spatial resolution in air pollution exposure data. ${ }^{2-4}$ However, it is only in small studies that it has been possible to measure pollution or exposure markers in blood at the individual level. ${ }^{26}$ Early studies compared pregnancy outcomes in a number of districts or counties with varying air pollution problems, usually with some data from existing monitoring stations that might have been very far away from the examined participants. Some studies restricted the study population to women living within a specified radius of a monitoring station. ${ }^{3}$ In later studies, data from areas with several monitoring sites were used with Kriging methods to create concentration maps, although the study population would sometimes be aggregated to the zip-code level. Home address has been used together with traffic flow data for proximity indicators, ${ }^{14}{ }^{17}$ or to estimate pollution exposure using a land use regression model, ${ }^{6} 71213$ or a dispersion model. ${ }^{8915}$

Some pollutants show large temporal variation due to weather and incoming air masses and smaller gradients within a city. In northern Europe, this is true for $\mathrm{PM}_{2.5}$ and ozone, with the major part being transported over a long distance. In order to study the important local sources and pollutants having large within-city gradients, such as motor vehicle exhaust, a fine spatial resolution is needed in the exposure data. Given the substantial spatial variation in traffic pollution concentrations it is motivated to use modelled data, from dispersion models, land-use regression models or traffic density measures, as the method for exposure assessment. These spatial contrasts in air pollution exposure also suggest a need to control for potential confounders associated with the type of residential area.

Two previous studies from Stockholm build only on temporal variation in air pollution concentrations, and found an association between first trimester ozone exposure and the incidence of preterm birth, ${ }^{10}{ }^{11}$ and pregnancy-induced hypertensive disorders. ${ }^{11}$ For motor vehicle exhaust exposure, using $\mathrm{NO}_{2}$ as an indicator, there was only an effect on preterm birth of $\mathrm{NO}_{2}$ in the last week of pregnancy. ${ }^{10}$ The variation in motor vehicle exhaust exposure was not described well enough described in these studies, but the good availability of individual data allows a further analysis of the more recent cohort using a different design.

The aim of this study was to study pregnant women's exposure to traffic exhaust pollutants at home in relation to the adverse pregnancy outcomes of spontaneous preterm delivery, pregnancy-induced hypertensive disorders and SGA births, using individual exposure estimates for outdoor concentrations of traffic air pollution within a large cohort.

\section{MATERIALS AND METHODS}

\section{Data}

All singleton live births in the Greater Stockholm area between 1998 and 2006 that were conceived between July 1997 and March 2006, whose mothers lived at the same address throughout the year prior to and at the time of delivery, were extracted from the Swedish Medical Birth Register. Using the Swedish personal identity number, data on maternal asthma were extracted from the Patient Register (1997-2010) and the Prescribed Drug Register (July 2005-December 2011). Statistics Sweden provided the level of the mother's education, and the location of the home in a fine-scale grid of $100 \mathrm{~m}^{2}$ (defined with coordinates), based on the geocoded home addresses from the National Population Register.

\section{Outcome definitions}

Spontaneous preterm delivery was defined as being delivered prior to the 37th week of gestation, where labour started spontaneously. SGA was defined as having a birth weight below the 10th centile of birth weights by gestation age (in days) and infant sex. ${ }^{27}{ }^{28}$ Gestational age is based on ultrasound examination for $>98 \%$ of the births in the Swedish Medical Birth Register. Pregnancy-induced hypertensive disorders were defined as having any of the International Classification of Diseases (ICD) 10 diagnostic codes: O11 pre-existing hypertension with preeclampsia, O13 gestational (pregnancy-induced) hypertension without significant proteinuria, O14 preeclampsia, for transient hypertension of pregnancy, O15 eclampsia.

\section{Variable definitions}

The mothers were defined as having asthma if they, according to the register data, had either or both of the ICD-10 diagnostic codes J45 and J46 or had been prescribed asthma medication (ATC codes R03AC, R03AK, R03BA, R03BC, R03CC and R03DC). Level of education was a five-level variable: pre-upper secondary school (9 years), upper secondary school (2 years), post-upper secondary school (<3 years), postsecondary school (3 years) and postgraduate education. Maternal region of origin was a six-category factor: Africa, the USA, Asia, and Oceania excluding the Middle East, Europe, the Middle East and the Nordic countries. Parity, that is, previous live births, was a four-level factor: 1, 2, 3 and 4 or more children. Maternal smoking was a three-level factor; non-smoker, moderate smoker $(<10$ cigarettes/day) and heavy smoker ( $\geq 10$ cigarettes/day). Family situation was a three-category factor: living alone, cohabiting with the father and other family situation. Body mass index (BMI) at the first antenatal visit was defined according to the WHO guidelines: underweight $\left(<18.5 \mathrm{~kg} / \mathrm{m}^{2}\right)$, normal weight $(\geq 18.5$ and $<25)$, overweight $(\geq 25$ and $<30)$ and obesity $(\geq 30)$. Owing to the previous findings, first trimester ozone concentration as the mean daily maximum $8 \mathrm{~h}$ concentration from two stations (Torkel 
Knutssonsgatan and Norr Malma) and mean temperature from three stations were entered as continuous variables. $^{11}$

\section{Exposure assessment}

Home address annual average NOx levels were calculated by using the SMHI-Airviro Gauss dispersion model and wind model, both of which are part of the Airviro Air Quality Management System. ${ }^{29}$ The SMHI-Airviro Gaussian model has been validated in several studies. ${ }^{30-32}$ The calculations were performed on a $100 \times 100 \mathrm{~m}$ resolution grid. The emission inventory of the Stockholm and Uppsala Air Quality Management Association supplied the input to the model. Information in this database has been updated yearly by the municipalities in the region since 1993. For the present study, only NOx emissions from road traffic were included to reflect vehicle exhaust levels. The road traffic emissions of NOx are described by using emission factors for different vehicles and road types obtained from the EVA model of the Swedish National Road Administration. The number of vehicles is given for different intersections of each street.

Average daily NOx levels from three monitoring stations at the rooftop level in different parts of the city (Hornsgatan, Sveavägen and Torkel Knutssonsgatan) were provided by the City of Stockholm Environment and Health Administration. The ratio between the annual (year of birth) NOx level at the home address and the mean of annual averages from the three monitoring stations was calculated for the year of birth. This individual ratio was used to estimate the average $\mathrm{NOx}$ levels during the first trimester, the last 6 weeks of gestation, the last 6 weeks at risk of preterm birth, and the full period of gestation, by multiplying the corresponding time period average from the monitoring stations with the ratio.

As an additional exposure estimate, the annual mean daily number of vehicles on the most heavily trafficked road within the $100 \mathrm{~m}^{2}$ of the home address was calculated using traffic flow data from the emission inventory of the Stockholm and Uppsala Air Quality Management Association.

\section{Statistical analysis}

Mixed model logistic regression was used to assess the association between the exposure variables and the pregnancy outcomes. Initially, we examined if the associations between exhaust and traffic variables and the outcomes of interest were linear by observing the estimated degrees of freedom and 95\% CIs from a penalised cubic spline; if they were not, we divided the exposure of interest into quartiles. For both vehicle exhaust and traffic flow and all outcomes, three models were fitted. The first, the unadjusted model, included only the exposure variable and a random intercept for municipality as explanatory variables. In model 2 , maternal asthma, maternal level of education, maternal region of origin, maternal age, parity, date of conception, first trimester ozone and first trimester temperature were included, where maternal age was a cubic spline function and date of conception was modelled with both a seasonal (cyclic spline function) and a long-term trend (cubic spline function). In model 3, we added adjustment for maternal smoking, maternal BMI at the first antenatal visit and family situation. As sensitivity analyses, we excluded women with pre-existing hypertension, and fitted the models with no random intercept. Statistical significance was judged on the basis of $95 \%$ CIs. All analyses were done using $\mathrm{R} 3.0 .1{ }^{33}$

\section{RESULTS}

The unadjusted model for the analysis of NOx and spontaneous preterm birth included 100190 participants. When restricting the analysis to participants with complete data on all covariates in model 3, the number of participants was reduced to 74991 . Similar reductions occur for the two other outcomes. In order to separate the effect of exclusion from the effect of adjustment, results from model 2 and the unadjusted analysis were calculated also for those with complete data only.

After exclusion of induced preterm deliveries, the proportion of spontaneous preterm births was $2.8 \%$ in the full data set, and $2.6 \%$ when restricted to study subjects with complete data on smoking, BMI or family situation. For SGA, the corresponding prevalences were $9.8 \%$ and $10.0 \%$, and for pregnancy-induced hypertensive disorders $2.7 \%$ and $2.6 \%$, respectively.

The average NOx level at the home addresses for the study subjects during the first trimester was $15.1 \mu \mathrm{g} / \mathrm{m}^{3}$ $(\mathrm{SD}=7.4)$, and the average maximal traffic flow within the $100 \times 100 \mathrm{~m}$ grid was 2569 vehicles/day $(\mathrm{SD}=7712)$. The spatial distribution of annual NOx averages is shown in figure 1. The IQR for the average NOx level at

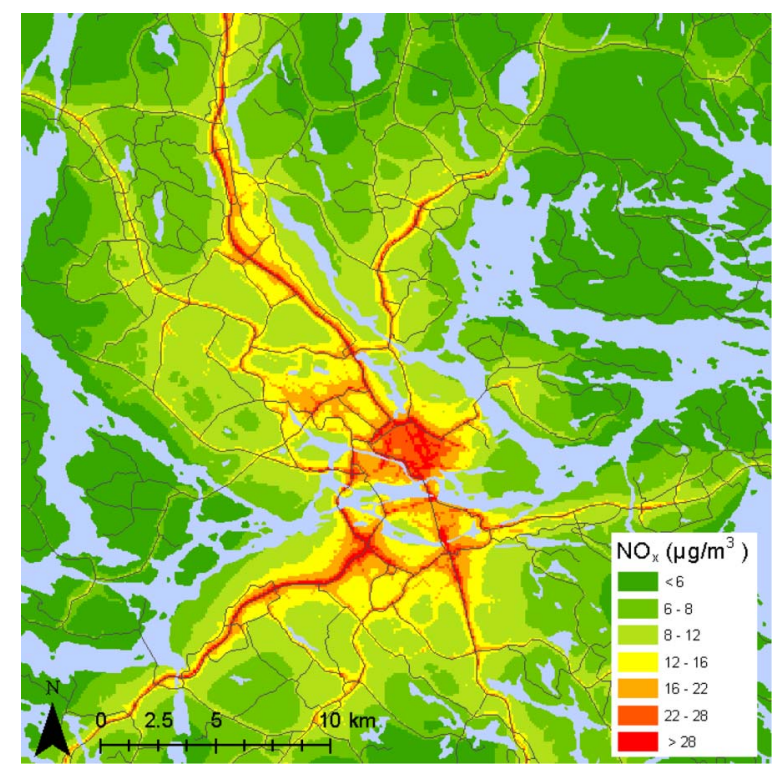

Figure 1 Map of the distribution of annual average nitrogen oxide (NOx) levels in Stockholm. 
the home address during the full period of gestation was 9.2, and for traffic flow the IQR was 3672. The correlation between the first trimester average NOx levels at the home address and traffic flow was 0.42 during the study period.

Our descriptive results supported the need to adjust for socioeconomic variables. Mothers born in Africa, Asia or the Middle East had a higher proportion of SGA and a lower average exposure to NOx than mothers born in the USA, Europe or the Nordic countries: $15.0 \%, 15.7 \%$ and $14.9 \%$ vs $9.5 \%, 10.5 \%$ and $8.5 \%$ for SGA, respectively, and $11.7,13.6$ and $11.7 \mu \mathrm{g} / \mathrm{m}^{3}$ vs 14.5 , 14.4 and $15.8 \mu \mathrm{g} / \mathrm{m}^{3}$ for NOx, respectively (table 1 ).

A number of favourable factors with respect to preterm birth and SGA were associated with higher levels of NOx, for example, being non-asthmatic, having a higher level of education, being a non-smoker and not being obese.

The correlation between the different time windows of NOx exposure was very high $(>0.9)$, which is why results for the different time windows cannot be distinguished, and only the results for the first trimester NOx are reported. There was a tendency for elevated average NOx levels to be associated with an increased risk of preterm birth, with an OR of 1.05 (95\% CI 0.98 to 1.13 ) per $10 \mu \mathrm{g} / \mathrm{m}^{3}$ increase in the NOx level in the fully adjusted model (table 2).

Higher NOx levels were associated with an increased risk for pregnancy-induced hypertensive disorders, with an OR of 1.12 (95\% CI 1.06 to 1.18 ) per $10 \mu \mathrm{g} / \mathrm{m}^{3}$ increase in the NOx level. The association was attenuated, though still statistically significant, after the first adjustment according to model 2 , but the association became stronger in the fully adjusted model 3. This increased OR may partly be due to missing data in the added variables, and partly due to confounding from maternal BMI (adjusting for BMI increased the OR from 1.12 to 1.17). Both the unadjusted model and model 2 showed stronger associations between the first trimester average NOx levels and pregnancy-induced hypertensive disorders when restricting the analysis to those study subjects who could be included in the fully adjusted model (with complete data on the variables added in model 3), $\mathrm{OR}=1.15$ versus 1.12 in the unadjusted model, and OR=1.13 versus 1.08 in model 2 .

A non-linear relation between air pollution exposure and the outcome was indicated only for NOx and SGA. In the unadjusted model, there was an increased odds of SGA births associated with the second quartile compared to the first quartile, while the association attenuated towards the null for the third and fourth quartiles (figure 2). In the two adjusted models, there were fairly constant significantly increased ORs for SGA for the second, third and fourth quartiles compared to the first quartile.

The pattern of associations between average annual daily traffic and the studied outcomes were, as expected, similar to the associations between average gestation
NOx levels and the studied outcomes (table 3). There was no association between higher average annual daily traffic and preterm birth or SGA in the adjusted models. The association between average annual daily traffic flow and pregnancy-induced hypertensive disorders was positive in all models, the strongest and borderline statistically significant in the fully adjusted model.

As in an earlier study of this population, ${ }^{11}$ the temporal variation in the first trimester ozone levels was associated with pregnancy-induced hypertensive disorders and preterm birth but not SGA (results not shown).

In this study, we used the possibility to study preterm birth with exclusion of induced preterm deliveries. However, for comparison, we did analyse preterm birth without this exclusion and found that the ORs were slightly closer to 1 when induced preterm deliveries were included (results not shown).

Excluding women with pre-existing hypertension did not alter the estimated associations. Allowing a random effect for municipality $(n=11$, of which the City of Stockholm is one) did not affect the estimated associations in consistent or significant ways.

\section{DISCUSSION}

Previous studies of air pollution and pregnancy outcomes in Stockholm had only temporal but no spatial resolution in the studied concentrations. This not only limits the potential confounders to time-varying factors, but also limits the study of vehicle exhaust. We observed a robust association between the pregnancy average NOx level at the home address and pregnancy-induced hypertensive disorders. The OR for an increase in NOx corresponding to the IQR was 1.16 (95\% CI 1.09 to $1.23)$ in the fully adjusted model. There was also an association between gestation average NOx and SGA; however, with the first quartile as a reference, the second, third and fourth quartiles were associated with similar increases in the odds. Without adjustment for the maternal region of origin, the increased risk in the two upper quartiles was not observed.

We observed weak evidence of an increased risk of preterm birth for women with elevated average levels of NOx from traffic at their home address. Traffic intensity also showed a tendency to be associated with small increases in the risk of pregnancy-induced hypertensive disorders, the $\mathrm{OR}$ associated with the IQR for traffic flow being 1.02 (95\% CI 1.00 to 1.04 ).

The mechanisms whereby air pollutants could increase the risk of these adverse pregnancy outcomes still need to be better understood. Air pollution exposure may influence maternal respiratory health and cardiovascular function as well as the placental function (oxygen and nutrient transport) and growth. An impaired placental function could be caused by oxidative stress, inflammation, coagulation, impaired endothelial function or haemodynamic responses. ${ }^{34} 35$ Women who were exposed to ambient air particles and ozone 


\begin{tabular}{|c|c|c|c|c|c|c|}
\hline & $\begin{array}{l}\text { Participants, } \\
\text { n }\end{array}$ & $\begin{array}{l}\text { Preterm } \\
\text { birth, \% }\end{array}$ & $\begin{array}{l}\text { SGA, } \\
\%\end{array}$ & $\begin{array}{l}\text { Pregnancy-induced } \\
\text { hypertensive } \\
\text { disorders, } \%\end{array}$ & $\begin{array}{l}\text { First trimester } \\
\text { average } \mathrm{NOx} \\
\text { levels, } \mu \mathrm{g} / \mathrm{m}^{3} \\
\text { (SD) }\end{array}$ & $\begin{array}{l}\text { Annual daily } \\
\text { average traffic } \\
\text { (year of birth), } \\
\text { vehicles/day (SD) }\end{array}$ \\
\hline \multicolumn{7}{|l|}{ Maternal asthma } \\
\hline Yes & 17981 & 3.1 & 9.8 & 3.1 & $14.9(7.2)$ & 3536 (7767) \\
\hline No & 84787 & 2.7 & 9.8 & 2.6 & $15.1(7.4)$ & $3576(7700)$ \\
\hline \multicolumn{7}{|l|}{ Maternal level of education } \\
\hline $\begin{array}{l}\text { Pre-upper secondary } \\
\text { school ( } 9 \text { years) }\end{array}$ & 9841 & 3.4 & 13 & 2.1 & $12.7(5.7)$ & $2516(6550)$ \\
\hline $\begin{array}{l}\text { Upper secondary } \\
\text { school ( } 2 \text { years) }\end{array}$ & 34755 & 3.0 & 10 & 2.9 & $14.3(7.0)$ & 3248 (7489) \\
\hline $\begin{array}{l}\text { Post-upper secondary } \\
\text { school (<3 years) }\end{array}$ & 16578 & 2.4 & 8.8 & 2.9 & $15.6(7.7)$ & 3800 (7978) \\
\hline $\begin{array}{l}\text { Post-secondary school } \\
\text { (3 years) }\end{array}$ & 38763 & 2.7 & 9.0 & 2.6 & $16.1(7.7)$ & $4032(8066)$ \\
\hline Postgraduate education & 1898 & 2.7 & 8.8 & 2.1 & $16.5(7.8)$ & 3697 (7107) \\
\hline \multicolumn{7}{|l|}{ Parity } \\
\hline 1 & 42870 & 2.9 & 11 & 2.9 & $15.4(7.5)$ & 3714 (7975) \\
\hline 2 & 38290 & 2.8 & 9.6 & 2.6 & $15.0(7.4)$ & 3502 (7483) \\
\hline 3 & 16225 & 2.4 & 8.4 & 2.3 & $14.6(7.2)$ & 3401 (7582) \\
\hline 4 or more & 5383 & 2.5 & 9.0 & 2.6 & $14.6(7.0)$ & $3390(7544)$ \\
\hline \multicolumn{7}{|l|}{ Maternal origin } \\
\hline Africa & 6815 & 2.2 & 15 & 1.7 & $11.7(4.2)$ & $1888(5140)$ \\
\hline USA & 2644 & 3.6 & 9.5 & 2.5 & $14.5(7.1)$ & 3135 (7004) \\
\hline Asia and Oceania & 5391 & 3.6 & 16 & 1.9 & $13.6(6.5)$ & 2817 (6538) \\
\hline Europe & 4376 & 2.6 & 11 & 1.6 & $14.4(7)$ & 3274 (7098) \\
\hline Middle East & 5806 & 3.1 & 15 & 1.7 & $11.7(4.8)$ & 2141 (6099) \\
\hline Nordic & 77334 & 2.7 & 8.5 & 3.0 & $15.8(7.7)$ & 3911 (8100) \\
\hline \multicolumn{7}{|l|}{ Maternal smoking } \\
\hline Non-smoker & 82565 & 2.6 & 9.6 & 2.7 & $14.9(7.2)$ & 3490 (7659) \\
\hline Moderate smoker & 4064 & 3.3 & 15 & 1.6 & $13.8(6.5)$ & 3098 (6960) \\
\hline Heavy smoker & 1540 & 3.3 & 19 & 1.8 & $13.1(5.8)$ & 2719 (7476) \\
\hline \multicolumn{7}{|c|}{ Maternal pre-pregnancy BMI } \\
\hline Underweight & 2363 & 2.9 & 18 & 1.1 & $15.4(7.6)$ & 3809 (7844) \\
\hline Normal weight & 56268 & 2.6 & 10 & 2.1 & $15.3(7.3)$ & 3683 (7828) \\
\hline Overweight & 16592 & 2.4 & 8.4 & 3.5 & $13.8(6.6)$ & $2950(7120)$ \\
\hline Obesity & 5664 & 2.7 & 8.7 & 5.8 & $12.9(5.9)$ & 2609 (6390) \\
\hline \multicolumn{7}{|l|}{ Family situation } \\
\hline Cohabiting & 84307 & 2.6 & 9.7 & 2.6 & $14.9(7.2)$ & $3478(7660)$ \\
\hline Living alone & 2250 & 2.6 & 13 & 2.2 & $13.5(5.9)$ & 2652 (6162) \\
\hline Other & 2664 & 3.5 & 14 & 2.9 & $14.2(6.7)$ & 3247 (7306) \\
\hline
\end{tabular}

Table 2 ORs for studied adverse pregnancy outcomes per $10 \mu \mathrm{g} / \mathrm{m}^{3}$ increase in the first trimester average nitrogen oxide (NOx) levels at the home address

\begin{tabular}{|c|c|c|c|c|c|c|}
\hline & \multicolumn{3}{|c|}{ Preterm birth } & \multicolumn{3}{|c|}{$\begin{array}{l}\text { Pregnancy-induced hypertensive } \\
\text { disorders }\end{array}$} \\
\hline & $\bar{n}$ & OR & $95 \% \mathrm{Cl}$ & $\bar{n}$ & OR & $95 \% \mathrm{Cl}$ \\
\hline Unadjusted model* & 100190 & 1.02 & 0.97 to 1.07 & 101900 & 1.12 & 1.06 to 1.18 \\
\hline Model $2 \dagger$ & 98895 & 1.04 & 0.98 to 1.09 & 100589 & 1.08 & 1.02 to 1.14 \\
\hline Model 3‡ & 74991 & 1.05 & 0.98 to 1.13 & 76116 & 1.17 & 1.10 to 1.26 \\
\hline \multicolumn{7}{|c|}{ Data set with complete information on explanatory variables } \\
\hline Unadjusted model ${ }^{*}$ & 74991 & 1.04 & 0.97 to 1.11 & 76116 & 1.15 & 1.08 to 1.23 \\
\hline Model $2 \dagger$ & 74991 & 1.05 & 0.99 to 1.13 & 76116 & 1.13 & 1.05 to 1.21 \\
\hline
\end{tabular}

${ }^{*}$ Includes a random effect for municipality.

†Adjusted for maternal asthma, maternal level of education, maternal area of origin, maternal age, first trimester temperature, first trimester ozone, day and year of conception, and parity.

$\ddagger$ Additionally adjusted for maternal smoking, body mass index and family situation. 
Figure 2 ORs for small for gestational age (SGA) by quartiles of the pregnancy average nitrogen oxide (NOx) levels at the home address. alncludes a random effect for municipality. bAdjusted for maternal asthma, maternal level of education, maternal area of origin, maternal age, first trimester temperature, first trimester ozone, day and year of conception, and parity. cAdditionally adjusted for maternal smoking, body mass index and family situation.
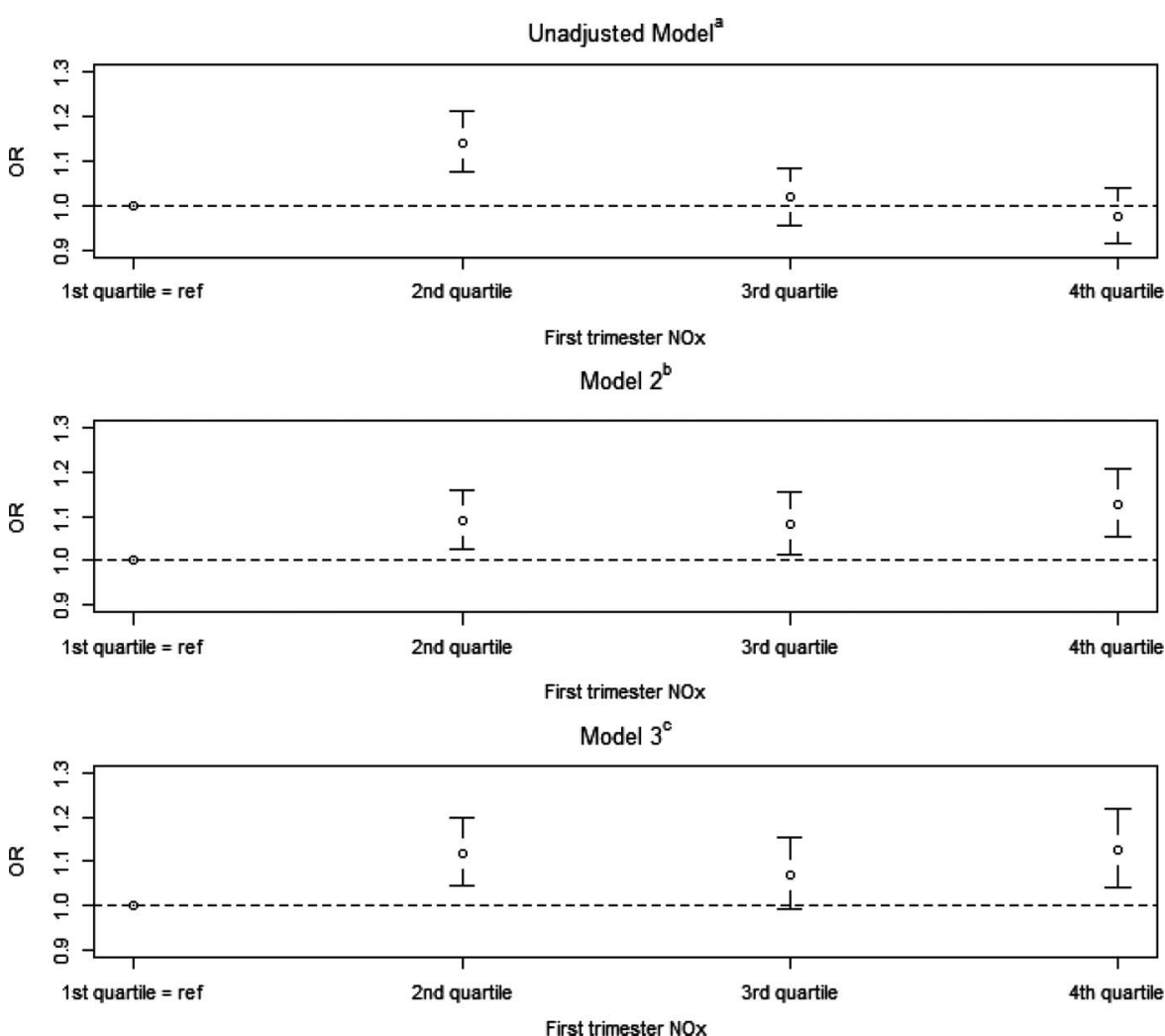

during early pregnancy are more likely to have elevated levels of $\mathrm{C}$ reactive protein levels, systematic inflammation driven by air pollution exposure being an underlying mechanism behind adverse birth outcomes. ${ }^{35}$ Trophoblastic invasion during formation of the placenta might be disrupted by proinflammatory cytokines. ${ }^{36} 37$ Air pollution in early pregnancy (first trimester) is of particular interest because this is the period when pollutants would be expected to interfere with maternal vascular remodelling processes. One hypothesis is that a principal cause of preeclampsia is a failed remodelling of the maternal spiral arteries supplying the placenta. ${ }^{38}$ A few studies have examined the associations between air pollution exposure and placental weight. Two found a negative effect associated with levels of $\mathrm{NO}_{2}$ and $\mathrm{PM}_{10}{ }^{39}$ and living within $200 \mathrm{~m}$ of a major road, ${ }^{16}$ and one study found inconsistent associations in two cities. ${ }^{40}$
In an earlier study from Stockholm focused on temporal variability in exposure, the concentration of $\mathrm{NO}_{2}$ during the last week of gestation was associated with gestational age and preterm delivery. ${ }^{1011}$ Unlike this study, in the previous study there was no evidence of an association between vehicle exhaust and pregnancy-induced hypertensive disorders. ${ }^{11}$ That study had no spatial resolution in the exposure assessment, so these results are not in conflict. Other studies have shown stronger associations between vehicle exhaust and preterm birth where the difference may arise either because the outcome was more common in those study populations or as a result of the indoor/outdoor ratio of the air pollution. ${ }^{7} \quad 15 \quad 17$ Pooled estimates for $\mathrm{NO}_{2}, \mathrm{CO}, \mathrm{PM}_{2.5}$ and $\mathrm{PM}_{10}$ have shown ORs for preterm birth in the range of 1.04-1.06 for an increase corresponding to a typical mean concentration. ${ }^{4}$ There are a few studies on vehicle exhaust and

Table 3 ORs for studied adverse pregnancy outcomes per 3000 vehicles/day increase at the home address

\begin{tabular}{|c|c|c|c|c|c|c|c|c|c|}
\hline & \multicolumn{3}{|c|}{ Preterm birth } & \multicolumn{3}{|c|}{ Small for gestational age } & \multicolumn{3}{|c|}{$\begin{array}{l}\text { Pregnancy-induced } \\
\text { hypertensive disorders }\end{array}$} \\
\hline & $\overline{\mathbf{n}}$ & OR & $95 \% \mathrm{Cl}$ & $\overline{\mathbf{n}}$ & OR & $95 \% \mathrm{Cl}$ & $\overline{\mathbf{n}}$ & OR & $95 \% \mathrm{Cl}$ \\
\hline Unadjusted model ${ }^{*}$ & 101003 & 1.00 & 0.98 to 1.01 & 101895 & 0.99 & 0.98 to 1.00 & 102726 & 1.01 & 1.00 to 1.03 \\
\hline Model $2 \dagger$ & 99703 & 1.00 & 0.99 to 1.02 & 100592 & 1.00 & 0.99 to 1.01 & 101410 & 1.01 & 0.99 to 1.02 \\
\hline Model 3† & 75599 & 1.00 & 0.99 to 1.02 & 76185 & 1.00 & 0.99 to 1.01 & 76735 & 1.02 & 1.00 to 1.03 \\
\hline
\end{tabular}

*Includes a random effect for municipality.

†Adjusted for maternal asthma, maternal level of education, maternal area of origin, maternal age, first trimester temperature, first trimester ozone, day and year of conception, and parity.

†Additionally adjusted for maternal smoking, body mass index and family situation. 
pregnancy-induced hypertensive disorders which report results similar to those in this study. ${ }^{5915}$ Our definition of pregnancy-induced hypertensive disorders differs slightly from previous publications in that we include O13, gestational hypertension (pregnancy-induced hypertension) without significant proteinuria. Pregnancy-induced hypertension constitutes a risk factor for development of preeclampsia, and is further associated with small-for-gestational age. There are other similar studies investigating the risk of SGA in relation to higher levels of vehicle exhaust, though one study from Oslo found no association. ${ }^{8}$ In general, the evidence for any association between $\mathrm{NO}_{2}$ or NOx, and SGA, low birth weight (LBW) or preterm birth has been inconclusive. ${ }^{3}$ However, a recent study with pooled data from 14 population-based mother-child cohorts in 12 European countries (74 178 deliveries) found the gestation mean level of $\mathrm{NO}_{2}$ at the home address to be associated with low birth weight at term; the OR for a $10 \mu \mathrm{g} / \mathrm{m}^{3}$ increase was 1.09 (95\% CI 1.00 to 1.19$){ }^{41}$

A strength of this study is the high resolution of the exposure data. Whereas many previous studies have mainly used data on county, zip-code level or locations within certain buffers around monitoring stations, we could pinpoint the address to a $100 \times 100 \mathrm{~m}$ grid and use the modelled level of vehicle exhaust for the same grid. We were also able to restrict the study to women who lived at the same address throughout their pregnancies. Additionally, we were able to adjust for individual factors correlated with both exposure and risk such as BMI, maternal origin and level of education, which might otherwise have acted as confounders, at least in the case of SGA. In this case, the least polluted areas are often suburbs with low status and a high proportion of immigrants from Africa and the Middle East and people with less education, while inner city residences are expensive and among the most exposed to vehicle exhaust, with a lower proportion of people suffering from obesity. We adjusted our models for the first trimester temperature since temperature is associated with air pollution levels, and extreme periods of warmer and colder days have been shown to be related to preterm deliveries. ${ }^{42} \mathrm{We}$ were also able to avoid most of the exposure misclassification stemming from residential mobility during pregnancy by restricting our study to those who lived at the same address for the year prior to delivery and at delivery.

We used the modelled concentration of NOx from road traffic at the home address as an indicator of traffic pollution; emissions from point sources such as power plants were not included due to tall stacks and the minor influence on local gradients in concentrations. A study comparing exposure assessment methods for traffic-related air pollution suggests that modelled NOx is more important for pregnancy-induced hypertensive disorders than particulate matter and a better exposure indicator than a simple traffic density measure. ${ }^{43}$ The rather high relative risk we found for pregnancy-induced hypertensive disorders (OR of 1.19 for $10 \mu \mathrm{g} / \mathrm{m}^{3}$ ) is for NOx from traffic.

One limitation is the very high correlation in $\mathrm{NOx}$ between exposure windows. We were unable to estimate how the association between NOx and the outcomes of interest varied throughout pregnancy. Furthermore, there may be exposure misclassification because we were not able to take commuting to a workplace into account in the exposure assessment. We may have excluded a potentially vulnerable subgroup by excluding all participants with a differing home address between conception and delivery.

To further explore the role of air pollution, we are planning a new study on a later study period using modelled concentrations of exhaust particles and black carbon at the home address.

\section{CONCLUSIONS}

In our study, NOx is used as a marker of traffic pollution and, in comparison with previous studies of preterm birth and pregnancy-induced hypertensive disorders, there was a marked effect of elevated NOx levels at the home address during pregnancy with the adverse pregnancy outcome pregnancy-induced hypertensive disorders, and a weaker evidence of associations between elevated NOx levels and preterm birth and SGA.

Contributors DO and BF designed the study. KE and DO constructed the database. All authors planned the analysis. DO undertook all statistical analysis and drafted the manuscript. IM, KE and BF helped to interpret and discuss the results and revise the manuscript. All authors approved the final manuscript.

Funding This study was supported by the ERA-ENVHEALTH Project ACCEPTED (Swedish funding agency: Naturvårdsverket (Swedish EPA)), CMF (Centre for Environmental Research, 0832336) in Umeå and the Umeå SIMSAM node.

Competing interests None declared.

Ethics approval Regional Ethical Review Board at Umeå University.

Provenance and peer review Not commissioned; externally peer reviewed.

Data sharing statement No additional data are available.

Open Access This is an Open Access article distributed in accordance with the Creative Commons Attribution Non Commercial (CC BY-NC 4.0) license, which permits others to distribute, remix, adapt, build upon this work noncommercially, and license their derivative works on different terms, provided the original work is properly cited and the use is non-commercial. See: http:// creativecommons.org/licenses/by-nc/4.0/

\section{REFERENCES}

1. Backes $\mathrm{CH}$, Nelin T, Gorr MW, et al. Early life exposure to air pollution: how bad is it? Toxicol Lett 2013;216:47-53.

2. Sapkota A, Chelikowsky A, Nachman K, et al. Exposure to particulate matter and adverse birth outcomes: a comprehensive review and meta-analysis. Air Qual Atmosphere Health 2012;5:369-81.

3. Shah PS, Balkhair T. Air pollution and birth outcomes: a systematic review. Environ Int 2011;37:498-516.

4. Stieb DM, Chen L, Eshoul M, et al. Ambient air pollution, birth weight and preterm birth: a systematic review and meta-analysis. Environ Res 2012;117:100-11.

5. Pedersen M, Stayner L, Slama R, et al. Ambient air pollution and pregnancy-induced hypertensive disorders: a systematic review and meta-analysis. Hypertension 2014;64:494-500. 
6. Ballester F, Estarlich M, Iniguez C, et al. Air pollution exposure during pregnancy and reduced birth size: a prospective birth cohort study in Valencia, Spain. Environ Health 2010;9:6.

7. Llop S, Ballester F, Estarlich M, et al. Preterm birth and exposure to air pollutants during pregnancy. Environ Res 2010;110:778-85.

8. Madsen C, Gehring U, Walker SE, et al. Ambient air pollution exposure, residential mobility and term birth weight in Oslo, Norway. Environ Res 2010;110:363-71.

9. Malmqvist $\mathrm{E}$, Jakobsson $\mathrm{K}$, Tinnerberg $\mathrm{H}$, et al. Gestational diabetes and preeclampsia in association with air pollution at levels below current air quality guidelines. Environ Health Perspect 2013;121:488-93.

10. Olsson D, Ekstrom M, Forsberg B. Temporal variation in air pollution concentrations and preterm birth - a population based epidemiological study. Int J Environ Res Public Health 2012;9:272-85.

11. Olsson D, Mogren I, Forsberg B. Air pollution exposure in early pregnancy and adverse pregnancy outcomes: a register-based cohort study. BMJ Open 2013;3:pii: e001955.

12. Pereira G, Haggar F, Shand AW, et al. Association between preeclampsia and locally derived traffic-related air pollution: a retrospective cohort study. J Epidemiol Community Health 2013;67:147-52.

13. Slama R, Morgenstern V, Cyrys J, et al. Traffic-related atmospheric pollutants levels during pregnancy and offspring's term birth weight: a study relying on a land-use regression exposure model. Environ Health Perspect 2007;115:1283-92.

14. Wilhelm M, Ritz B. Residential proximity to traffic and adverse birth outcomes in Los Angeles county, California, 1994-1996. Environ Health Perspect 2003;111:207-16.

15. Wu J, Ren C, Delfino RJ, et al. Association between local traffic-generated air pollution and preeclampsia and preterm delivery in the south coast air basin of California. Environ Health Perspect 2009;117:1773-9.

16. Yorifuji $\mathrm{T}$, Naruse $\mathrm{H}$, Kashima $\mathrm{S}$, et al. Residential proximity to majo roads and placenta/birth weight ratio. Sci Total Environ 2012;414:98-102.

17. Yorifuji $\mathrm{T}$, Naruse $\mathrm{H}$, Kashima $\mathrm{S}$, et al. Residential proximity to major roads and adverse birth outcomes: a hospital-based study. Environ Health 2013;12:34.

18. Behrman RE, Butler AS, eds. Preterm birth: causes, consequences, and prevention: The National Academies Press, 2007.

19. Ekeus $\mathrm{C}$, Lindstrom $\mathrm{K}$, Lindblad $\mathrm{F}$, et al. Preterm birth, social disadvantage, and cognitive competence in Swedish 18- to 19-year-old men. Pediatrics 2010;125:e67-73.

20. Lindstrom K, Winbladh B, Haglund B, et al. Preterm infants as young adults: a Swedish national cohort study. Pediatrics 2007;120:70-7.

21. Vogt $\mathrm{H}$, Lindstrom $\mathrm{K}$, Braback $\mathrm{L}$, et al. Preterm birth and inhaled corticosteroid use in 6- to 19-year-olds: a Swedish national cohort study. Pediatrics 2011;127:1052-9.

22. Kanasaki K, Kalluri R. The biology of preeclampsia. Kidney Int 2009;76:831-7.

23. Uzan J, Carbonnel M, Piconne O, et al. Pre-eclampsia: pathophysiology, diagnosis, and management. Vasc Health Risk Manag 2011; 7:467-74.

24. Lau C, Rogers JM. Embryonic and fetal programming of physiological disorders in adulthood. Birth Defects Res C Embryo Today 2004;72:300-12

25. Janssen NA, Hoek G, Simic-Lawson M, et al. Black carbon as an additional indicator of the adverse health effects of airborne particles compared with PM10 and PM2.5. Environ Health Perspect 2011;119:1691-9.

26. Morales E, Gascon M, Martinez D, et al. Associations between blood persistent organic pollutants and 25-hydroxyvitamin D3 in pregnancy. Environ Int 2013;57-58:34-41.

27. De Jong CL, Francis A, Van Geijn HP, et al. Customized fetal weight limits for antenatal detection of fetal growth restriction. Ultrasound Obstet Gynecol 2000;15:36-40.

28. Groom KM, Poppe KK, North RA, et al. Small-for-gestational-age infants classified by customized or population birthweight centiles: impact of gestational age at delivery. Am J Obstet Gynecol 2007;197:239 e1-5.

29. SMHI. Modules [cited 2014 March 31]. http://www.smhi.se/airviro/ modules/

30. Eneroth $\mathrm{K}$, Johansson C, Bellander T. Exposure comparison between measurements and calculations based on dispersion modelling (EXPOSE). Stockholm Environment and Health Protection Administration, 2006.

31. Johansson C, Andersson C, Bergström R, et al. Exposure to particles due to local and non-local sources in Stockholm: estimates based on modelling and measurements 1997-2006. ITM RAPPORT. 2008;(175).

32. Johansson $\mathrm{C}$, Hadenius $\mathrm{A}$, Johansson $\mathrm{P}$, et al. SHAPE the Stockholm study on health effects of air pollution and their economic consequences. Part I. Stockholm Environment and Health Protection Administration. 1999(2)

33. R Core Team. R: a language and environment for statistical computing Vienna, Austria: R Foundation for Statistical Computing, 2013.

34. Kannan S, Misra DP, Dvonch JT, et al. Exposures to airborne particulate matter and adverse perinatal outcomes: a biologically plausible mechanistic framework for exploring potential effect modification by nutrition. Environ Health Perspect 2006;114:1636-42.

35. Lee PC, Talbott EO, Roberts JM, et al. Particulate air pollution exposure and C-reactive protein during early pregnancy. Epidemiology 2011;22:524-31.

36. Gitto E, Reiter RJ, Karbownik M, et al. Causes of oxidative stress in the pre- and perinatal period. Biol Neonate 2002;81:146-57.

37. Hansen C, Neller A, Williams G, et al. Maternal exposure to low levels of ambient air pollution and preterm birth in Brisbane, Australia. BJOG 2006;113:935-41.

38. Roberts JM, Gammill HS. Preeclampsia: recent insights. Hypertension 2005;46:1243-9.

39. van den Hooven EH, Pierik FH, de Kluizenaar $\mathrm{Y}$, et al. Air pollution exposure and markers of placental growth and function: the generation R study. Environ Health Perspect 2012;120:1753-9.

40. Rahmalia A, Giorgis-Allemand L, Lepeule J, et al. Pregnancy exposure to atmospheric pollutants and placental weight: an approach relying on a dispersion model. Environ Int 2012;48:47-55.

41. Pedersen M, Giorgis-Allemand L, Bernard C, et al. Ambient air pollution and low birthweight: a European cohort study (ESCAPE). Lancet Respir Med 2013;1:695-704.

42. Vicedo-Cabrera AM, Olsson D, Forsberg B. Exposure to seasonal temperatures during the last month of gestation and the risk of preterm birth in Stockholm. Int J Environ Res Public Health 2015;12:3962-78

43. Wu J, Wilhelm M, Chung J, et al. Comparing exposure assessment methods for traffic-related air pollution in an adverse pregnancy outcome study. Environ Res 2011;111:685-92. 